\title{
Attitudes of Employed Mothers Towards Early Childhood Education for Children
}

\author{
Dr. Ayesha Batool \\ Lecturer (Visiting), Institute of Education and Research, University of the Punjab, Lahore Pakistan \\ Saghir Ahmad \\ $\mathrm{PhD}$ Scholar, Institute of Education and Research, University of the Punjab, Lahore Pakistan
}

\begin{abstract}
Parents play vital role in the field of broad and informal teaching of their children. The children follow the behaviors and attitudes of their parents. Certain family customs and attitude have an everlasting impression on the mental abilities of the children. Parental involvement is considered as a sign of Parental attitude. The main purpose of the study was to explore the attitude of working mothers about their children education. This study was quantitative in nature. Sample was consisted of sixty teachers. A five point Likert type scale was used to collect the data. Mean, One Way ANOVA and t-test were applied to analyze the data. The major finding of the study indicated that mostly working mothers have positive attitude towards the education of their children, they thought their children inspired from them and get more interest in their study. It also revealed that working mothers taught their children properly, and checked their homework daily.
\end{abstract}

Keywords: Parents, attitude, working mothers, children

DOI: $10.7176 /$ RHSS/9-9-04

Publication date:May $31^{\text {st }} 2019$

\section{Introduction}

Education can be taught of the transmission of the values and accumulates knowledge of the society. We receive education both formally in schools and other institutions of teaching and informally at home. Family plays an important role and contacts with other people. Education is the process by which an individual gain knowledge of insight or develop attitudes and skills. It is a process to attain acculturation through which the individual is helped to attain the development of his potentialities and their maximum activation necessary. Early Childhood Education is a term that refers to educational programs and strategies geared toward children from birth to the age of eight. This time period is commonly considered the most at risk and critical stage of a person's life. Early childhood education consists of activities or firsthand experiences that are projected to effect developmental changes in children proceeding to their entry into elementary school (Anwenwu, 1999).

Mother is the more cohesive in development of the child as a unique individual. Mothers were target on their responsibilities of child rearing and education. In developed countries early childhood education programs have been the focus of much research. For such programs the economic case can be made on two reasons. The first is that of equity. In terms of employment, income growth, Individuals who begin life with very unequal endowments of human capital are likely to end up with very unequal results, etc. By seeking trying to do so equalize starting points or initial endowments of human capital a government has seeks to deal with the inequality on outcomes (Canole, 2013).

Mothers have received and continue to receive a lot of consideration regarding their influence on children's growth, development and well-being. This attention to mother's importance and role in child learning, education and life outcomes is proper and acceptable. Mother-child relationships are important and determine the path of development in childhood. There is also receiving some of the employment benefits that have traditionally gone only to women. Family attachment is the strongest interpreter of child educational outcomes. This aspect is directly related with children's inspiration to learn, attention, task determination, approachable vocabulary skills, and low carry out problems. Mother's contribution in education has been recognized as a helpful factor in young children's learning (National Research Council, 2001).

It is, therefore, a key factor of national educational policies and early childhood programs. Much of the research on parent involvement, as it relates to children's outcomes, has emphasized the bond between specific mother contribution behaviors and children's achievement. Mother concern at school (e.g., with school activities, direct communication with teachers and administrators) is related with greater achievement in mathematics and reading. Higher levels of mother involvement in their children's educational experiences at home (e.g., supervision and monitoring, daily conversations about school) have been connected with children's higher attainment scores in reading and writing, as well as higher report card grades (Wong \& Hughes, 2006).

The attitude of the employed mother signifies that the supporting nature of family in their children's education. The employed mother's attitude can be negative or positive. The negative attitude of the mother about education and schooling can turn away their children from getting education. With less mother support in school 
work, low level of motivation and poor self-esteem of children can result. Positive attitude of the mother can be helpful to their children in many cases and can be reflected in improvement in class performance, creating interest between children to learn, and higher attainment scores in reading and writing (Goldberg, 2000). The developing awareness about education makes many families value their children's education and act favorably towards schooling and education of their children. They become a part of the decision making process of school, and choose their children's future regarding higher education.

Considerable research at least twenty five years has verified that mother involvement is important to the educational success of children (Kniepkamp, 2005). To detail on that result is an additional conclusion from the research. When schools recognize the significance of children's homes and cultures and encourage mother involvement, they can develop an encouraging environment for learning through important activities that engage and give power to employed mothers (Rhodes, Enz, \& LaCount, 2006). In employed-mother families, such gender-based differences in childrearing are less common. In the Michigan study across social class, we found that, employed mothers in difference with full-time homemakers, showed less differentiation between sons and daughters in their authority style and in their goals for their children. We also find that employed mothers, compared to full-time homemakers, were more likely to refer to independence as an aim for their daughters and less likely to specify that "obedience" or "to be feminine" was their aim. And, mothers who cited the aim of obedience, or the goal "to be feminine", were more likely to have daughters who were shy, nonassertive in the classroom, and had a lower sense of efficiency, while refer to the goal of independence showed the opposite effects (Sroufe, 1988).

In psychology and education, employed mother attitudes toward childrearing have been broadly studied and of great importance in understanding child development and socialization (Kagitcibasi \& Sunar, 2002), particularly since employed mother attitudes are often regarded as indicators of parent behavior or parent-child relations. This phenomenon has a key topic in examinations of parent-child interactions quickly developed (Holden \& Edwards, 1989). An increasing number of studies have focused on the mutual relationship between mother attitudes and culture. For example, Suizzo (2002) stated that mother attitudes and in turn a child's socio cultural development reveal differences from culture to culture.

\section{Significance of Study}

The findings of this study may be useful for the mothers and family members in the society. The study may fruitful for the mothers to encourage their children and explore their horizons through paying more attention to them. It may help them to identify the problems faced by them during their learning process and find out the solution. This study may provide attention to mothers to help out their children in learning. The findings of the study may be useful in explaining the attitudes of mothers towards children education.

\section{Research Objectives}

The study was conducted to achieve the following objectives to:

1. Examine the attitudes of employed mothers towards early childhood education for children.

2. Find out the demographic difference in mothers attitudes towards early childhood education for children.

\section{Research Methodology}

It was a descriptive research and Survey method was used in this study. Descriptive involves collecting data in order to test hypothesis or answer questions relating to the current status of the study. The population of the study was all the employed mothers having school going children of Lahore city. It was consisted of the government or private schools teachers. Schools were selected purposively from the selected towns. Then sixty teachers were selected from schools by using conveniently sampling technique. A five point Likert type scale was designed for assembling responses of the selected sample. Data were collected personally from the respondents. Descriptive (frequency, mean scores, and standard deviations) and inferential statistical techniques (independent sample t-test and one way ANOVA) were applied to analyze the data.

\section{Data Analysis}

The detail of data analysis is given below.

Table 1

Sample Description of the Study on the Basis of Qualification

\begin{tabular}{ccc}
\hline Qualification & Frequency & Percent \\
\hline B.A/B.Sc & 25 & 41.7 \\
M.A/M.Sc & 30 & 50.0 \\
M.Phil & 5 & 8.3 \\
Total & 60 & 100.0 \\
\hline
\end{tabular}

Table shows that $41 \%$ teachers qualification in the sample was B.A/B.Sc, $50 \%$ were M.A/M.Sc and $8 \%$ 
were M,Phil degree. So it concluded that the majority of the teachers Qualification were M.A/M.Sc degrees.

Table 2

Sample Description of the Study on the Basis of Sector

\begin{tabular}{ccc}
\hline Nature of Job & Frequency & Percent \\
\hline Private Job & 40 & 66.7 \\
Government Job & 20 & 33.3 \\
Total & 60 & 100.0 \\
\hline
\end{tabular}

Table shows that $66 \%$ teacher were private job and 33\% teachers were government job in the sample, So it is concluded that there were more teachers private job in the sample than Government Job.

Table 3

Sample Description of the Study on the Basis of Year of Employment

\begin{tabular}{ccc}
\hline Experience & Frequency & Percent \\
\hline 1 to 10 & 49 & 81.7 \\
11 to 20 & 8 & 13.3 \\
21 to 30 & 3 & 5.0 \\
Total & 60 & 100.0 \\
\hline
\end{tabular}

Table describes that $81 \%$ teachers were 1-10 years of employment, $13 \%$ teachers were 11-20 years of employment, and $5 \%$ teaches were 21 to 30 year of employment. So it concluded that the majority of the teachers were 1-10 years of employment.

Table 4

Employed Mothers Attitudes towards Children Education

\begin{tabular}{|c|c|c|}
\hline Statements & Mean & $S D$ \\
\hline Are you content with your job & 1.53 & .676 \\
\hline Your family members are cooperative & 1.30 & .462 \\
\hline Is your home environment comfortable for your children studies & 1.40 & .807 \\
\hline Are your children interested in getting education & 1.22 & .454 \\
\hline Your children get inspiration from you & 1.32 & .504 \\
\hline You know about your child school system & 1.33 & .475 \\
\hline You are interested in your children academic progress & 1.08 & .279 \\
\hline You teach your child at home & 1.55 & .928 \\
\hline Are you satisfied with the tutor or care giver of your child? & 2.73 & 1.326 \\
\hline You are used to meet your child teacher weekly & 1.78 & 1.166 \\
\hline You check your child homework daily & 1.40 & .827 \\
\hline $\begin{array}{l}\text { You often discuss your child progress/performance with his/her tutor or care } \\
\text { giver }\end{array}$ & 1.85 & 1.147 \\
\hline Is your child satisfied with his/her school system & 1.77 & .767 \\
\hline Is your child satisfied with his/her tutor or caregiver & 2.03 & .956 \\
\hline Your child is satisfied with his/her school teacher & 1.75 & .654 \\
\hline You have friendly attitude with your child & 1.10 & .303 \\
\hline You give enough time to your child for studies & 1.65 & .840 \\
\hline You think your employment have bad effects on your child early education & 3.65 & 1.494 \\
\hline You think your employment have good effects on your child early education & 2.02 & 1.255 \\
\hline $\begin{array}{l}\text { Do you think if you are employed you can teach your child better than his/her } \\
\text { tutor or caregiver }\end{array}$ & 2.08 & 1.197 \\
\hline Performance of your child is better than children of unemployed mothers & 1.97 & 1.248 \\
\hline $\begin{array}{l}\text { In your opinion there is much difference in children achievement of employed } \\
\text { and unemployed mothers }\end{array}$ & 1.60 & 1.092 \\
\hline
\end{tabular}

Table 5

Comparison of Teachers Opinion on the Basis of Sector

\begin{tabular}{lcccccc}
\hline Sector & $\boldsymbol{N}$ & Mean & $\boldsymbol{S D}$ & $\boldsymbol{t}$-value & $\boldsymbol{d} \boldsymbol{f}$ & $\boldsymbol{S i g}$. \\
\hline Private Job & 40 & 39.4500 & 8.00945 & 1.977 & 58 & .162 \\
Government Job & 20 & 35.4500 & 5.90695 & & & \\
\hline
\end{tabular}

Table indicates that $p$ value is not significance $(p=.162)$ at 0.05 level of significant. Therefore it is concluded there is no significant difference between perceptions of private and government teachers respect to employed mothers attitudes towards children education. 
Table 6

One way ANOVA to Check the Experience Difference

\begin{tabular}{lccccc}
\hline & Sum of Squares & $\boldsymbol{d f}$ & Mean Square & $\boldsymbol{F}$ & Sig. \\
\hline Between Groups & 7.204 & 2 & 3.602 & .061 & .941 \\
Within Groups & 3370.980 & 57 & 59.140 & & \\
Total & 3378.183 & 59 & & & \\
\hline
\end{tabular}

This table shows that $F=.061$ and $p=.941$ there is no significant difference between employed mothers attitude on the basis of their employment experience. In other words years of employment does not affect the employed mothers' attitude.

Table 7

Comparison of Perception of the Teachers on the Basis of Qualification regarding Employed Mothers of Attitudes

\begin{tabular}{lccccc}
\hline & Sum of Squares & $\boldsymbol{d f}$ & Mean Square & $\boldsymbol{F}$ & Sig. \\
\hline Between Groups & 85.943 & 2 & 42.972 & .744 & .480 \\
Within Groups & 3292.240 & 57 & 57.759 & & \\
Total & 3378.183 & 59 & & & \\
\hline
\end{tabular}

This table shows that $F=.744$ and $p=.480$ there is no significant difference between employed mothers attitude on the basis of their qualification. In other words qualification does not affect the employed mother's attitude towards their children education.

\section{Conclusion}

After completion of the study regarding attitudes of employed mothers towards their children education at early childhood education, the results show that employed mothers have positive attitude, and devoted interest towards their children education at early years. Maternal employment, in itself, is unlikely to have unfavorable effects on the huge majority of young children. Working mothers can be quite successful at establishing safe and sound relationship with their infants and toddlers if they give back for their lack of available time for their children by being predominantly sensitive and responsive. A mother's work activities and her temporary absence from the home have any regular effects on her children's education. Although employed mothers have positive attitudes towards the education of their children at ECE and have friendly attitude with their children. They are also used to check their child's homework daily, teach them at home and give quick response to their children when they show good performance. Employed mothers have interest in their children's academic process and they are well aware of the school system. Children of employed mothers have interest to learn new things from school and home. The employed mothers create positive attitude in their children towards education. Usually the children are satisfied with school system and teachers and they discuss all their academic problems with their mothers. Family members of the employed mothers are cooperative and as a result the home environment is comfortable for children's learning. There is not much difference in the opinions of employed mothers whether they are government employed or private but attitudes of employed mothers in government schools towards their children education is slightly better than the attitude of employed mothers in non-government schools. So, it is concluded from this study that almost all the employed mothers have positive attitude towards education of their children.

\section{Recommendations}

Following recommendations are made on the basis of the study findings:

1. It is very important for mothers to recognize that until the child moves away from her and establishes a home of his or her own, she happens to the person on whom the sound wellbeing of the child rests.

2. A child attains the age when he or she starts going to school, teachers and trainers in addition to private tutors play a major responsibility in the life of a child. Unfortunately, several mothers feel that responsibility is not as critical as it was during the birth followed by the period in which the child is totally dependent on the mother.

3. When parents are involved in their children's education at home, they do better in school.

4. The family makes significant involvement to student achievement from pre-school to high school. A home environment that encourages learning is more important to student achievement than income, education level or cultural back ground.

5. Three kinds of parental involvement at home are consistently connected with higher student achievement: actively organizing and monitoring a child's time by helping with homework and discussing school matters.

\section{References}

Annanwu, H. M. (1991). Educational change. New York: Hercort B Race. 
Canole, G. (2013). Pedagogical planners. In designing for learning in an open world. Explorations in learning sciences, instructional systems and performance technologies. Springer New York, 4, 183-202

Colin, V. L. (1996). Human attachment. Tokyo: The McGraw-Hill Companies, Inc.

Goldberg, S. (2000). Attachment and development. London: Oxford University Press Inc.

Hinkle, D. (2000). School involvement in early childhood. US Government Printing Office, Superintendent of Documents, Mail Stop: SSOP, Washington, DC 20402-9328. ED Pubs, PO Box 1398, Jessup, MD 207941398.

Holden \& Edwards (1989). Parental attitudes towards childrearing. Handbook of Parenting: Being and Becoming a Parent, 2(3), 545-554.

Kagitcibasi, C., \& Sunar (2002). Child rearing and self-esteem in Turkish families: Perspectives on human development, family and culture. Early childhood Education in Turkey, 1(2), 337-348.

Kniepkamp, (2005). Developing a planning schedule. Families and educators as partners: Issues and challenges (2nd ed.). Wadsworth, Belmont, USA Press. 270-274.

Lehman, T. M. (2001). Late Cretaceous dinosaur provinciality. Mesozoic Vertebrate life, $310,328$.

National Research Council. (2001). Eager to learn: Educating our preschoolers. National Academies Press.

Rhodes, M., Enz, B., \& LaCount, M. (2006). Leaps and bounds: Preparing parents for kindergarten. YC Young Children, 50-51.

Sroufe, L. A. (1988). A developmental perspective on day care. Early Childhood Research Quarterly, 3(3), 283291.

Suizzo. (2002). Parental Ethno-theories. Socio-Emotional Development in Cultural Context, 1(8), 82-92.

Verma, S., \& Konantambigi, R. (2011). Chapter thirty four. The Wiley-Blackwell Handbook of Childhood Social Development, 646.

Wilson, R. A. (2003). Special educational needs in the early years. New York: Rutledge flamer Taylor \& Francis Group.

Wong, S. W., \& Hughes, J. N. (2006). Ethnicity and language contributions to dimensions of parent involvement. School Psychology Review, 35(4), 645-662. 